\title{
Preparation of Active Carbon by Additional Activation with Potassium Hydroxide and Characterization of Their Properties
}

\author{
Bronislaw Buczek \\ Faculty of Energy and Fuels, AGH University of Science and Technology, Mickiewicz Avenue 30, 30-059 Cracow, Poland \\ Correspondence should be addressed to Bronislaw Buczek; bbuczek@agh.edu.pl
}

Received 15 November 2015; Revised 8 January 2016; Accepted 10 January 2016

Academic Editor: Jainagesh A. Sekhar

Copyright ( 2016 Bronislaw Buczek. This is an open access article distributed under the Creative Commons Attribution License, which permits unrestricted use, distribution, and reproduction in any medium, provided the original work is properly cited.

\begin{abstract}
A commercially available activated carbon was used to prepare active carbon via reactivation with $\mathrm{KOH}$ at $750^{\circ} \mathrm{C}$. Active carbon was obtained with $60.5 \%$ yield. The resulting active carbon showed a well-developed porous structure with specific surface area $2939 \mathrm{~m}^{2} / \mathrm{g}$, total pore volume $1.488 \mathrm{~cm}^{3} / \mathrm{g}$, and micropore volume $1.001 \mathrm{~cm}^{3} / \mathrm{g}$. Process reactivation of carbon changes its particle size as well as density properties and increases by nearly twice the amounts of methane and carbon dioxide adsorbed under high pressure conditions. Such active carbon may be used to enrich methane or carbon dioxide by pressure swing adsorption technique. Other possible applications of reactivated carbon are storage of hydrogen and methane and sequestration of carbon dioxide.
\end{abstract}

\section{Introduction}

Activated carbons are produced from different precursors, such as wood, peat, brown coal, lignite, various types of hard coal, anthracite, carbo- and petrochemical products, polymers, and fruit shells $[1,2]$. Typically, all organic precursor can be converted into activated carbons; however, in most cases, it requires the usage of an activation agent and only a few are commercially attractive. The properties of the final product depend on the nature of raw material used, the nature of activating agent, and the conditions of activation process.

The traditional production of activated carbon consists of two steps: (i) carbonization of the precursor at a temperature below $900^{\circ} \mathrm{C}$ in inert atmosphere and (ii) chemical or physical chemical activation of the carbonized precursor [3].

In the chemical activation process, either the previously carbonized product is impregnated with suitable chemical agents, such as acids $\left(\mathrm{HNO}_{3}, \mathrm{H}_{2} \mathrm{SO}_{4}\right.$, and $\left.\mathrm{H}_{3} \mathrm{PO}_{4}\right)$ or salts $\left(\mathrm{ZnCl}_{2}, \mathrm{MgCl}_{2}, \mathrm{FeCl}_{3}, \mathrm{AlCl}_{3}\right.$, and $\left.\mathrm{K}_{2} \mathrm{~S}\right)$. These reagents act by solubilized cellulose, which, at elevated temperatures, separates, as a highly dispersed amorphous carbon, which forms a porous structure in the carbonaceous adsorbent.

When the chemical treatment is carried out with sulphuric acid at temperatures $<200^{\circ} \mathrm{C}$, the active carbon shows poor sorption capabilities. During activation with phosphoric acid at $375-500^{\circ} \mathrm{C}$, corrosion problems appear with the equipment. One drawback of activation with zinc chloride at $550-650^{\circ} \mathrm{C}$ is that the active carbon is polluted with zinc salts, which are difficult to remove.

Amoco Corporation developed a process to produce high surface area carbons (over $3000 \mathrm{~m}^{2} / \mathrm{g}$ ) by the $\mathrm{KOH}$ activation of aromatic precursors such petroleum coke and coal. The process was commercialized in the 1980s and was subsequently licensed and operated on pilot plant by the Kansai Coke and Chemicals Co. At this time, only limited quantities of products have been produced. The activated carbon is predominantly microporous, which is responsible for high surface area, and the total pore volume is exceptionally high: $2.0-2.6 \mathrm{~mL} / \mathrm{g}[4]$.

Increasing interest in activation with potassium hydroxide from such precursors as wood and vegetable shells has led to investigations of the chemistry and mechanism of formation of activated carbon with a perfectly developed porous structure and a very high specific surface area [5].

The paper presents the results of studies on increasing the adsorption capacity of a commercial active carbon for methane and carbon dioxide by additional activation with potassium hydroxide. 


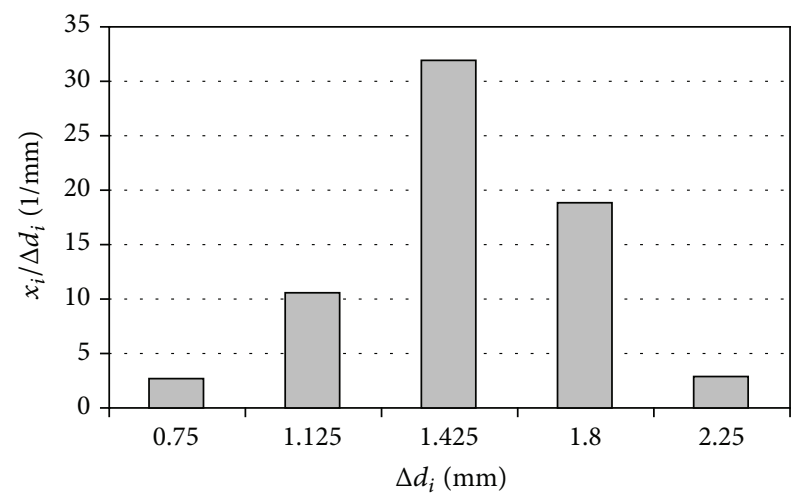

Pic

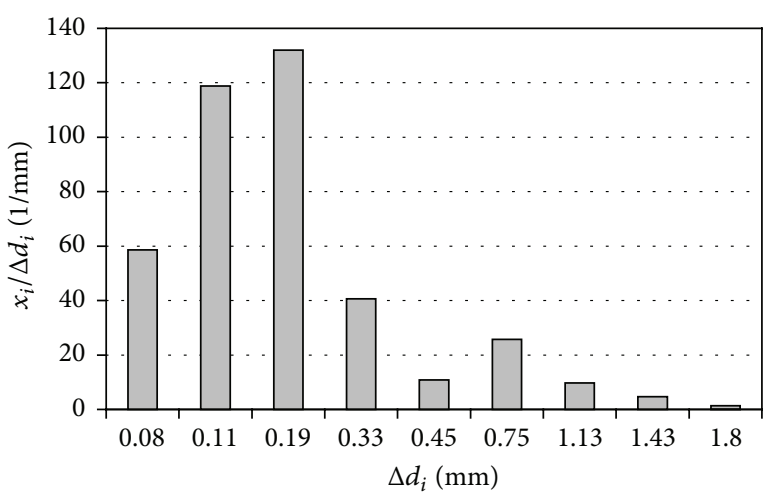

Pic K

(a)

(b)

FIgURe 1: Sieve analysis of Picazine and Picazine K.

\section{Experimental}

2.1. Material and Reactivation with $\mathrm{KOH}$. The material for the additional chemical treatment was Picazine active carbon [6] manufactured from pinewood by Société PICA, France. The original chemical activation was done using orthophosphoric acid.

2.1.1. Reactivation of Active Carbon. Picazine carbon was dried and then mixed with ground $\mathrm{KOH}$ in the ratio $1: 3(\mathrm{~m} / \mathrm{m})$. The treatment was carried out in a muffle furnace at a temperature of $750^{\circ} \mathrm{C}$ in an atmosphere of neutral gas $\left(\mathrm{N}_{2}\right)$. The mixture was rapidly heated to $700^{\circ} \mathrm{C}$, and then the temperature was raised to $750^{\circ} \mathrm{C}$ at a rate of $10^{\circ} \mathrm{C} / \mathrm{min}$. After this temperature was attained, the reaction mixture was held for $30 \mathrm{~min}$, and then it was cooled to ambient temperature. All the time, the neutral gas $\left(\mathrm{N}_{2}\right)$ was flowing inside the furnace at a rate of $30 \mathrm{~L} / \mathrm{min}$. When the reaction mixture reached ambient temperature, it was neutralised with $5 \% \mathrm{HCl}$ solution. The carbon modified in this way gave the solution a green colour that remained during the initial period of washing. After each subsequent wash out of the potassium base, the suspension was decanted, diluted with distilled water, and its $\mathrm{pH}$ value was measured. This treatment was repeated several times, until the $\mathrm{pH}$ of the filtrate reached 6.5. When the specified $\mathrm{pH}$ was achieved, the active carbon was separated from the solution by filtration under reduced pressure of 10-15 $\mathrm{mmHg}$, rinsing the filter cake with distilled water, which was then dried at a temperature of $120^{\circ} \mathrm{C}$. The modified product was obtained with a yield of $60.5 \%(\mathrm{~m} / \mathrm{m})$. The $\mathrm{KOH}$ modified active carbon was denoted by Picazine K.

\section{Evaluation of Properties Active Carbon and Product of Reactivation}

3.1. Sieve Analysis. In order to determine the size distribution of the particles of both active carbons, size analysis was performed [7] for both active carbons (Figure 1).
TABLE 1: Densities, porosity, and total porosity of active carbons.

\begin{tabular}{lcc}
\hline Properties & Picazine & Picazine K \\
\hline Bulk density $\left(\rho_{n}\right), \mathrm{g} / \mathrm{cm}^{3}$ & 0.204 & 0.120 \\
Apparent density $\left(\rho_{p}\right), \mathrm{g} / \mathrm{cm}^{3}$ & 0.450 & 0.325 \\
Real density $\left(\rho_{r}\right), \mathrm{g} / \mathrm{cm}^{3}$ & 1.777 & 2.669 \\
Pore volume $(V), \mathrm{cm}^{3} / \mathrm{cm}^{3}$ & 1.660 & 2.702 \\
Total porosity $\left(\varepsilon_{c}\right), \mathrm{cm}^{3} / \mathrm{cm}^{3}$ & 0.885 & 0.995 \\
\hline
\end{tabular}

The results, and the calculated values of the equivalent diameter, prove that Picazine carbon undergoes far-reaching disintegration as a result of high-temperature $\mathrm{KOH}$ treatment, and the product obtained shows two predominant particle sizes (ca. 0.2 and $0.7 \mathrm{~mm}$ ). A change in the particle size of the active carbons, as well as the modification itself, significantly affects the values of different kind of densities.

3.2. Densities Measurements. Important properties of adsorbents are their densities: bulk density $\left(\rho_{n}\right)$, apparent density $\left(\rho_{p}\right)$, and real density $\left(\rho_{r}\right)$. Bulk density was determined by Powder Characteristics Tester [8], apparent density was determined by using mercury displacement, and real density was determined by GeoPyc 1330 Envelope Density Analyzer [9].

Pore volumes $(V)$ for both carbons were calculated from $\rho_{p}$ and $\rho_{r}$ using the following equation:

$$
V=\frac{1}{\rho_{p}}-\frac{1}{\rho_{r}} .
$$

Total porosity $\left(\varepsilon_{c}\right)$ that includes the volume of interparticle space and the volume present inside adsorbent particles was determined from the following relation:

$$
\varepsilon_{c}=1-\frac{\rho_{n}}{\rho_{r}} .
$$

The results of density determination and the values calculated from (1) and (2) are given in Table 1. 


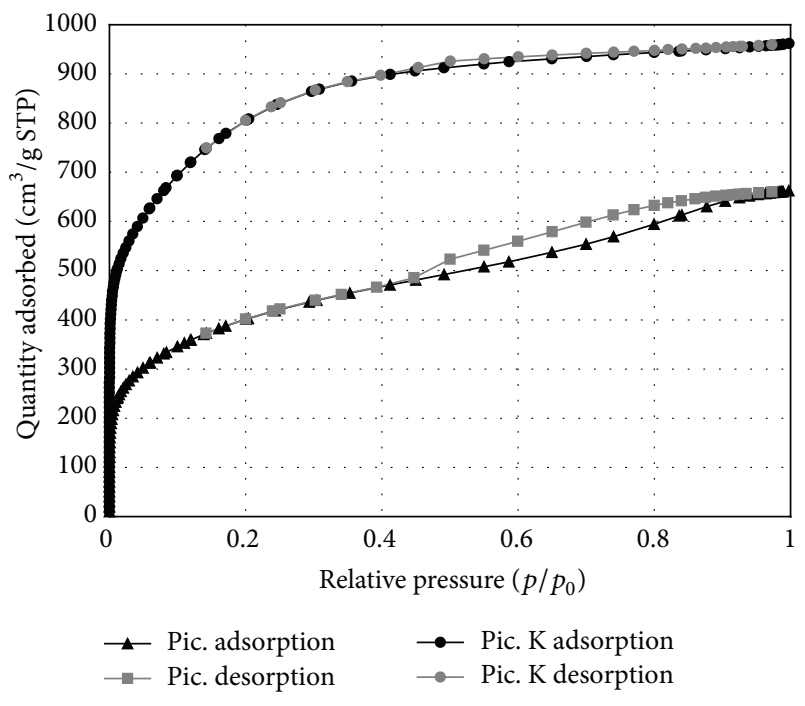

FIGURE 2: Adsorption-desorption isotherm of active carbons.

It is clear from Table 1 that the reduction of potassium hydroxide to metallic potassium [10] may cause an increase in $\rho_{r}$ for Picazine $\mathrm{K}$, and, in this way, affect the value of the pore volume and total porosity.

The porous structure of the carbons was analysed by lowtemperature nitrogen adsorption. Adsorption-desorption isotherms were determined using ASAP 2020 Micromeritics instrument. The measurements were carried out at $77 \mathrm{~K}$ in the pressure range $p / p_{0}$ of $0.00001-0.999$. Both active carbon isotherms are shown in Figure 2.

The volume of micropores $\left(W_{0}\right)$, characteristic energy of adsorption $\left(E_{0}\right)$, and surface area micropores $\left(S_{\mathrm{mi}}\right)$ were determined according to Dubinin-Radushkevich equation [11], mesopores surface area $\left(S_{\mathrm{me}}\right)$ and volume mesopores $\left(V_{\mathrm{me}}\right)$ were determined by BJH method [12], and the specific surface was obtained using the BET equation. The results are summarized in Table 2.

The treatment of Picazine carbon with potassium hydroxide caused increase in its structural parameters. The highest increase was found in the case of micropores, surface area, and total pore volume. In consequence, the volume of mesopores decreases, so did their surface area. The increase in the characteristic adsorption energy $E_{0}$ is mainly due to the narrowing of micropore size as a result of $\mathrm{KOH}$ reactivation. Using calculations micropore size by McEnaney equation [13] it was found that, for adsorption energy $E_{0}=16.22$, size micropores amount to $0.40 \mathrm{~nm}$, and, for $E_{0}=17.77$, size equals $0.36 \mathrm{~nm}$ in slit pore model.

The adsorbent obtained has significantly better structural properties than the initial active carbon.

3.3. Adsorption of Methane and Carbon Dioxide. For both active carbons, methane and carbon dioxide adsorption isotherms were determined using the volumetric method at a pressure of up to $3 \mathrm{MPa}$ using an original measuring apparatus [14]. The measurement principle consisted in the expansion of a gas of known pressure and volume from the
TABLE 2: Structural parameters of active carbons.

\begin{tabular}{lcc}
\hline Active carbon & Picazine & Picazine K \\
\hline BET surface area, $\mathrm{m}^{2} / \mathrm{g}$ & 1462 & 2939 \\
Total pore volume, $V_{t} \mathrm{~cm}^{3} / \mathrm{g}, p / p_{0}=0.99$ & 1.024 & 1.488 \\
Micropore volume, $W_{0}, \mathrm{~cm}^{3} / \mathrm{g}$ & 0.494 & 1.001 \\
Energy of adsorption, $E_{0}, \mathrm{~kJ} / \mathrm{kmol}$ & 16.22 & 17.77 \\
Surface area micropores, $S_{\mathrm{mi}}, \mathrm{m}^{2} / \mathrm{g}$ & 1392 & 2817 \\
Mesopores surface area, $S_{\mathrm{me}}, \mathrm{m}^{2} / \mathrm{g}(\mathrm{BHJ})$ & 226 & 88 \\
Volume mesopores, $V_{\mathrm{me}}, \mathrm{cm}^{3} / \mathrm{g}(\mathrm{BHJ})$ & 0.288 & 0.089 \\
\hline
\end{tabular}

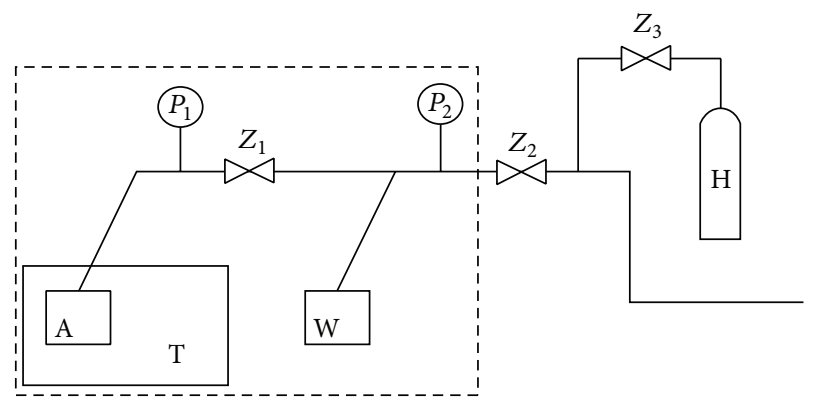

FIGURE 3: Apparatus used for adsorption gases at elevated pressure. A: phial with adsorbent, $\mathrm{T}$ : thermostat, $\mathrm{H}$ : gas cylinder, $\mathrm{W}$ : feeder, $P_{1}, P_{2}$ : pressure measurements, and $Z_{1}, Z_{2}$, and $Z_{3}$ : control valves.

dosing space into the adsorbent containing ampoule. Figure 3 shows the apparatus for studying sorption and desorption gases under elevated pressures.

The determination of the so-called excess isotherms was carried out at $25^{\circ} \mathrm{C}$. The molar volume of the gas for a given pressure and temperature was calculated using the BeattieBridgeman equation that well describes the state of methane and carbon dioxide in the studied pressure and temperature range [15].

Figure 4 presents excess adsorption isotherms of methane and carbon dioxide on the original and modified Picazine.

Treating Picazine carbon with potassium hydroxide nearly doubled the adsorption capacity for $\mathrm{CH}_{4}$ and $\mathrm{CO}_{2}$, as calculated from 3.0 MPa isotherms.

From the technical point of view, the purpose of Picazine $\mathrm{K}$ carbon in the pressure range $0-1.0 \mathrm{MPa}$ may be $\mathrm{CO}_{2}$ separation from the biogas using the PSA method and coalmine gas or nitrogen-containing natural gas enrichment with methane.

At a pressure of $3 \mathrm{MPa}$ and beyond, additionally activated carbons may found application for storage of fuels and sequestration of $\mathrm{CO}_{2}$ [16].

\section{Conclusions}

A significant increase in the adsorption capacity of Picazine active carbon, an active carbon manufactured on an industrial scale from wood, results from additional potassium hydroxide chemical activation.

The carbon thus obtained possesses nearly double the adsorption capacity for methane and carbon dioxide. The 


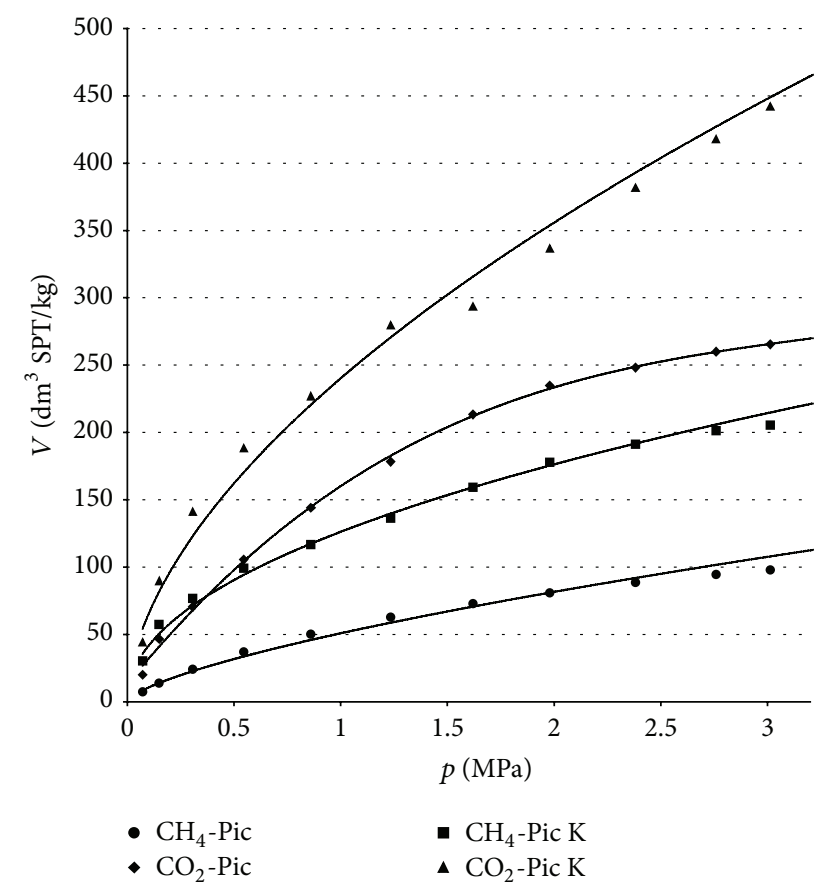

Figure 4: Isotherms of methane and carbon dioxide on Picazine and Picazine K.

porous structure parameters of the active carbon determined prior to and after the modification process correlate very well with the high-pressure adsorption values for both gases.

The product of the reactivation may be used for instance for gaseous fuel storage and for separation of nonliquefying gases using the PSA method.

\section{Conflict of Interests}

The author declares that there is no conflict of interests regarding the publication of this paper.

\section{Acknowledgment}

The author is grateful to the AGH University of Science and Technology (Project no. 11.11.210.244) for the financial support of the research described in this paper.

\section{References}

[1] F. Derbyshire, M. Jagtoyen, and M. Thwaites, "Activated carbonproduction and applications," in Porosity in Carbons, J. W. Patrick, Ed., pp. 228-239, Edward Arnolds, London, UK, 1995.

[2] W. Tongpoothorn, M. Sriuttha, P. Homchan, S. Chanthai, and C. Ruangviriyachai, "Preparation of activated carbon derived from Jatropha curcas fruit shell by simple thermo-chemical activation and characterization of their physico-chemical properties," Chemical Engineering Research and Design, vol. 89, no. 3, pp. 335-340, 2011.

[3] P. Kleszyk, P. Ratajczak, P. Skowron et al., "Carbons with narrow pore size distribution prepared by simultaneous carbonization and self-activation of tobacco stems and their application to supercapacitors," Carbon, vol. 81, no. 1, pp. 148-157, 2015.

[4] F. Derbyshire, M. Jagtoyen, R. Andrews, A. Rao, I. MartinGullón, and E. A. Grulke, "Carbon materials in environmental applications," Chemistry and Physics of Carbon, vol. 27, pp. 1-66, 2000 .

[5] B. Buczek and E. Wolak, "Potassium hydroxide modified active carbon for adsorptive refrigerators," Adsorption, vol. 14, no. 2-3, pp. 283-287, 2008.

[6] A. Perrin, A. Celzard, J. F. Marêché, and G. Furdin, "Improved methane storage capacities by sorption on wet active carbons," Carbon, vol. 42, no. 7, pp. 1243-1249, 2004.

[7] T. Allen, Particle Size Measurement, Chapman and Hall, London, UK, 1984.

[8] B. Buczek and E. Vogt, "An experimental procedure and apparatuses for measurement of density of density of porous particles," in Characterisation of Porous Solids III, Studies in Surface Science and Catalysis, J. Rouquerol, F. Rodriguez-Reinoso, K. S. W. Sing, and K. K. Unger, Eds., vol. 87, pp. 339-344, Elsevier, Amsterdam, The Netherlands, 1994.

[9] P. Webb and C. Orr, Analytical Methods in Fine Particle Technology, Micromeritics Instrument, Norcross, Ga, USA, 1997.

[10] Y. Otowa, Y. Nojima, and M. Itoh, Activation Mechanism, Surface Properties and Adsorption Characteristics of Koh Activated High Surface Area, Fundamentals of Adsorption, Kluwer Academic, Boston, Mass, USA, 1996.

[11] M. M. Dubinin, "Adsorption properties and microporous structures of carbonaceous adsorbents," Carbon, vol. 25, no. 5, pp. 593-598, 1987.

[12] E. P. Barrett, L. G. Joyner, and P. P. Halenda, "The determination of pore volume and area distributions in porous substances. I. Computations from nitrogen isotherms," Journal of the American Chemical Society, vol. 73, no. 1, pp. 373-380, 1951.

[13] B. McEnaney, "Estimation of the dimensions of micropores in active carbons using the Dubinin-Radushkevich equation," Carbon, vol. 25, no. 1, pp. 69-75, 1987.

[14] A. Nodzeński, "Sorption and desorption of gases $\left(\mathrm{CH}_{4}, \mathrm{CO}_{2}\right)$ on hard coal and active carbon at elevated pressures," Fuel, vol. 77, no. 11, pp. 1243-1246, 1998.

[15] R. C. Reid and T. K. Sherwood, The Properties of Gases and Liquids, McGraw-Hill, New York, NY, USA, 1974.

[16] D. Damiani, J. T. Litynski, H. G. McIlvried, D. M. Vikara, and R. D. Srivastava, “The US Department of Energy's R\&D program to reduce greenhouse gas emissions through beneficial uses of carbon dioxide," Greenhouse Gases: Science and Technology, vol. 2, no. 1, pp. 9-19, 2012. 

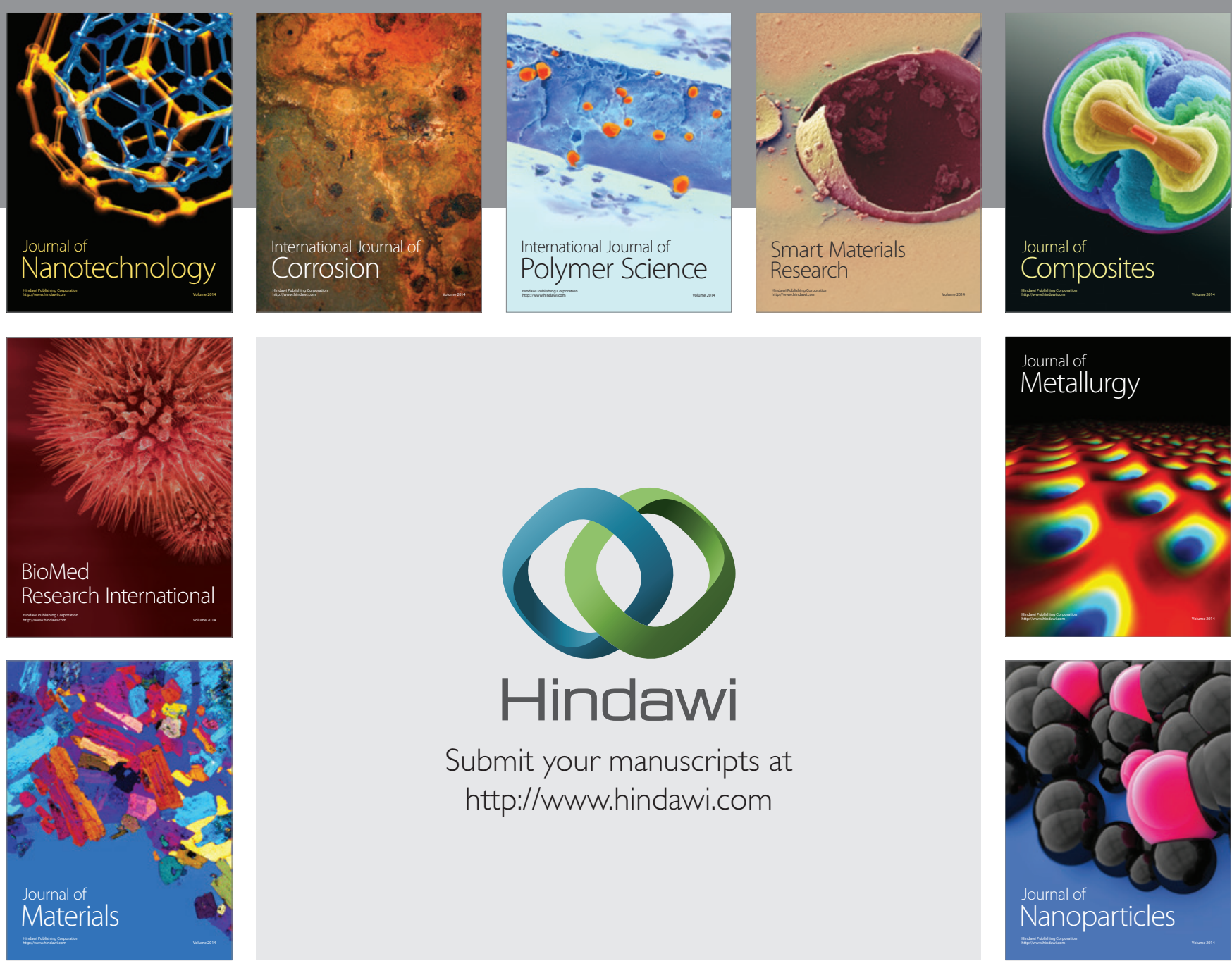

\section{Hindawi}

Submit your manuscripts at

http://www.hindawi.com

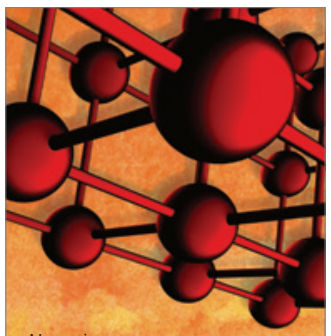

Materials Science and Engineering
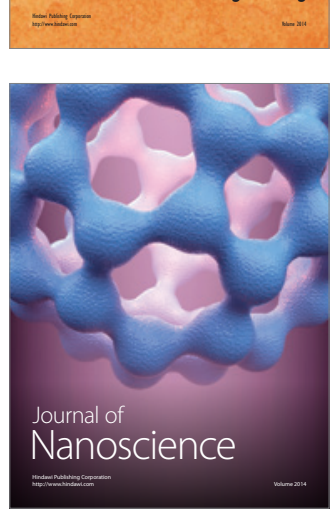
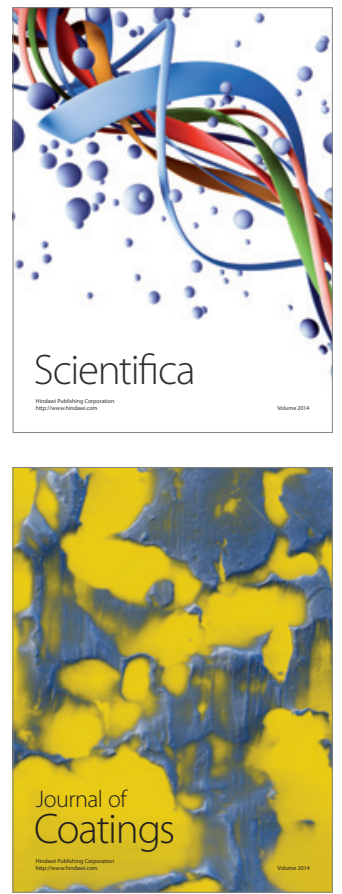
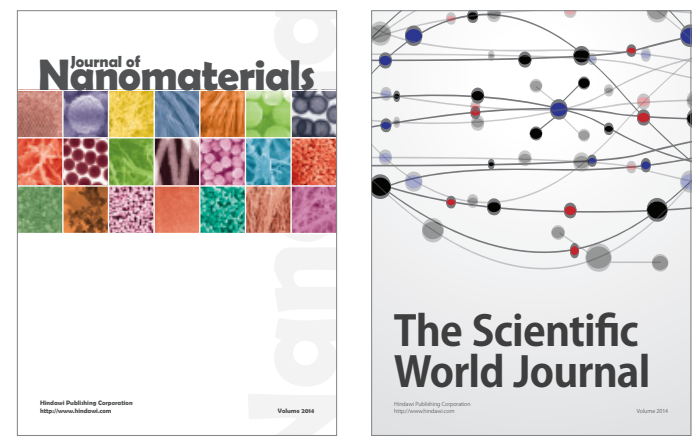

The Scientific World Journal
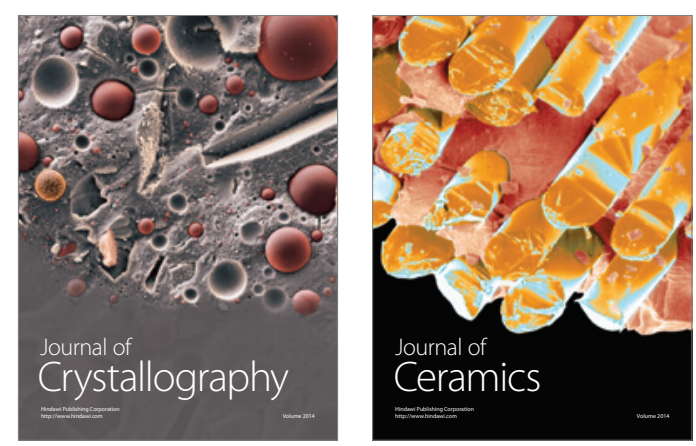
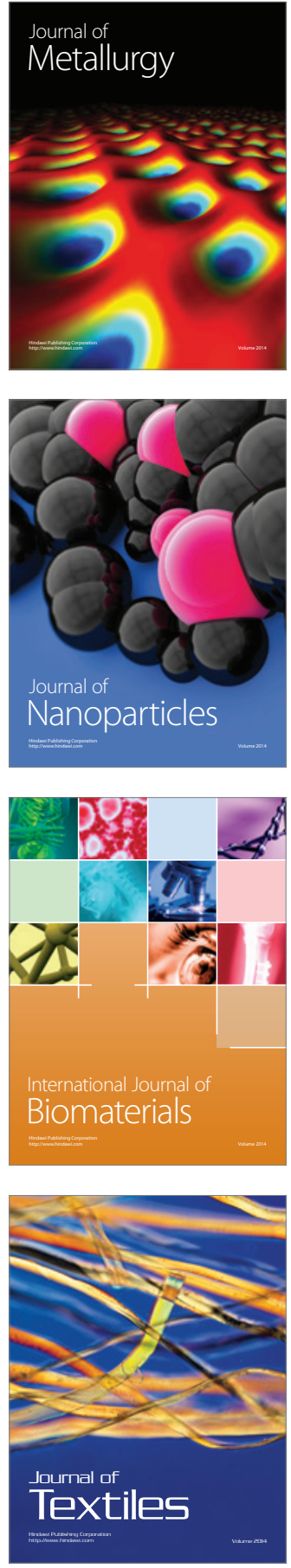